\title{
A política nacional de humanização e o desenrolar do fio da esperança equilibrista ${ }^{1}$
}

The national policy of humanization and the unwinding of the wire tightrope walker hope

La política nacional de humanización y el desarrollo del hilo de la esperanza equilibrista

\section{Carolina Eidelwein}

Universidade Federal do Rio Grande do Sul, Porto Alegre, RS, Brasil.

\begin{abstract}
Resumo
O presente artigo analisa uma experiência de apoio institucional proposta pelo curso de Especialização em Humanização da Atenção e Gestão do Sistema Único de Saúde (SUS) no estado do Rio Grande do Sul. Reflete sobre a criação de condições para a inserção de dispositivos da Política Nacional de Humanização (PNH) do Ministério da Saúde em um serviço de Saúde Mental, a partir de uma pesquisa-intervenção fundamentada pelo arcabouço teórico-metodológico da PNH. Relaciona o modelo de atenção psicossocial com a política de humanização, particularmente com sua diretriz da co-gestão, referendando o argumento de que a capilarização da PNH passa necessariamente pela constituição de grupalidades e pelo trabalho em redes.
\end{abstract}

Palavras-chave: Humanização; Formação; Co-gestão; Saúde Mental; Apoio Institucional.

\begin{abstract}
The present article analyzes an experience of institucional support through the specialist degree course in Humanization for Care and Management in the Brazilian Unified Health System. It reflects on the creation of conditions for insertion of the National Humanization Policy (NHP) devices in a Mental Health service, grounded by a research-intervention based on the NHP theory and methodology. It relates the model of psychosocial attention with the humanization for care, particularly with its co-management' guideline, reaffirming the argument that the NHP capillarity necessarily passes by the constitution of collectives and social networks.
\end{abstract}

Keywords : Humanization ; Training ; Co-management ; Mental Health; Institucional Support.

\section{Resumen}


Este artículo analiza una experiencia de apoyo institucional propuesta por el curso de Especialización en Humanización de la Atención y Gestión del Sistema Único de Salud brasileño en el estado de Rio Grande del Sur. Reflexiona sobre la creación de condiciones para la inserción de dispositivos de la Política Nacional de Humanización (PNH) del Ministerio de la Salud brasileño en un servicio de salud mental, a través de una investigaciónintervención fundamentada en el marco teórico y metodológico de la PNH. Relaciona el modelo de atención psicosocial a la política de humanización en salud, en particular a su diretriz de co-gestión, reafirmando el argumento de que la implementación efectiva de la PNH implica necesariamente la formación de grupos y el trabajo con las redes comunitarias.

Palabras claves: Humanización; Formación; Co-Gestión; Salud Mental; Apoyo Institucional.

\section{Introdução}

Este trabalho debate a função do apoio institucional no agenciamento de coletivos para a inserção da Política Nacional de Humanização do SUS (PNH) nas práticas em Saúde Mental de um Município da Região Metropolitana de Porto Alegre RS. Trata-se de um relato da experiência como apoiadora institucional da PNH em um Centro de Atenção Psicossocial (CAPS II), a partir do curso de especialização em Humanização da Atenção e da Gestão do SUS. Este cursointervenção realizou-se entre os anos de 2008 e 2009, viabilizado por meio de uma parceria entre o Ministério da Saúde, a Universidade Federal do Rio Grande do Sul e a Escola de Saúde Pública da Secretaria Estadual de Saúde do Rio Grande do Sul.
O curso em questão apresentava a proposta metodológica de inserção dos alunos como apoiadores institucionais nos próprios municípios em que eram trabalhadores do SUS, com o objetivo de construção de uma intervenção a partir da análise do cenário e da análise de suas implicações, a fim de que pudessem dar início ou continuidade ao trabalho com a PNH nesses locais.

A intervenção aqui discutida teve seu foco delimitado a partir do mapeamento do cenário - a organização do serviço e da rede municipal de saúde onde este se insere - e do rumo tomado pelos acontecimentos durante o processo do curso. Antes de realizarmos a opção pelo trabalho com um dispositivo específico, entre os dispositivos ofertados pela $\mathrm{PNH}$, deparamo-nos com a necessidade de criar condições para que a equipe do serviço em que nos inserimos como apoiadora pudesse se colocar como protagonista de seus 
processos de trabalho. Avaliamos que o trabalho seria eminentemente micropolítico, tendo a diretriz da CoGestão como norteadora da intervenção.

Buscamos refletir sobre a criação dessas condições para uma possível oferta de dispositivos da PNH a esse serviço de Saúde Mental, ao relacionar o modelo de atenção psicossocial com a política de humanização. Partimos da idéia de que estas condições passariam necessariamente pela constituição de grupalidades e pelo trabalho em redes - que também são pontos fundamentais para a desinstitucionalização da loucura. Entendemos que a função do apoio institucional tenha a potencialidade de colocar na roda esse debate.

\section{Adentrando o cenário}

Nossa intervenção aconteceu em um município com cerca de 200 mil habitantes, localizado na região metropolitana de Porto Alegre - RS, no qual historicamente a assistência em saúde vinha sendo constituída de forma centralizada, a partir de serviços de atenção especializada e com capacidade quantitativamente inferior às necessidades em saúde da região. Ao mesmo tempo, a gestão nesse campo vinha caracterizandose pela concentração de poder, através de um organograma excessivamente enxuto e da ausência de sistematização de uma política municipal de saúde. Os cargos de gestão eram eminentemente políticopartidários, sendo rarefeitas as coordenações técnicas dos serviços. As instâncias de participação social no município pareciam refletir as marcas históricas impressas por políticas assistencialistas de governo.

Naquela época, a gestão municipal estava investindo na descentralização dos serviços e na ampliação da atenção básica. A rede de atenção encontrava-se em expansão, mas não era possível descrever avanços no que diz respeito ao modelo de gestão. Assim, ao analisarmos o cenário sob a perspectiva da $\mathrm{PNH}$, eram candentes os entraves vivenciados na rede municipal de saúde. Pela inexistência de uma construção coletiva e democrática de uma política pública de saúde no município, cada profissional e cada serviço operava de acordo com uma lógica idiossincrática, que geralmente dava prioridade a interesses privatistas em detrimento do compromisso social com a produção de saúde. Os dispositivos da PNH que traduzem práticas engajadas com o acolhimento, a clínica ampliada, as equipes de referência, a cogestão, os direitos dos usuários, o trabalho 
com redes sociais e a valorização do trabalho em saúde passavam ao longe da maioria dos serviços. Em nosso percurso de trabalho nesse município, experimentávamos a contribuição decisiva dos elementos ora apontados para a fragmentação da atenção e da gestão experimentada nos serviços de saúde.

A lógica que permeava aquela gestão - e a atenção, à medida que ambas se encontram num regime de inseparabilidade - era predominantemente instrumental, baseada no modelo biomédico, fundamentada em uma moral asséptica que desconsiderava os sujeitos envolvidos no processo de produção de saúde - tanto os usuários quanto os trabalhadores do SUS no município.

Nesse sentido, a opção pelo trabalho micropolítico inserido na equipe de profissionais do CAPS deu-se pelo diagnóstico de que o cenário colaborava decisivamente para o predomínio de uma lógica de individualização e de desresponsabilização entre os trabalhadores, inclusive como defesa diante da precarização das condições de trabalho e do adoecimento. Em termos empregatícios, os trabalhadores da saúde tinham seu papel legitimado: eram servidores públicos em regime estatutário, com cargos estabelecidos pela legislação municipal. Essa precarização a que nos referimos era sutil - estava implícita nas relações de trabalho - e consistia no próprio apagamento dos trabalhadores enquanto sujeitos, à medida que experimentavam cotidianamente a desconsideração de seus saberes e de suas potencialidades para a construção e cogestão de uma política pública.

Assim, aproximando-nos da função apoio institucional (Campos, 2007) pudemos mapear a necessidade de fomento do protagonismo e autonomia junto aos trabalhadores, com vistas a ampliação da transversalidade e da grupalidade naquele coletivo, como condição para a inserção dos aportes da PNH no serviço de saúde mental em questão.

Esse serviço, onde teve lugar nossa intervenção, vinha passando por um processo gradativo de democratização das relações, com o favorecimento da análise dos processos de trabalho e construção de um modo de cuidar a partir do modelo psicossocial. Esse processo tomava corpo principalmente nas reuniões da equipe de profissionais, que ocorriam semanalmente através de rodas onde eram discutidos os casos clínicos, os processos de trabalho e também as questões administrativas. Avaliamos que alguns dos movimentos aqui apontados já estavam em curso no cenário da intervenção e foram catalisados a partir do processo do apoio institucional, 
outros foram disparados no decorrer do percurso.

Mesmo partindo desses espaços potentes de trabalho, sempre que envolviam a instância ampliada de gestão, as pactuações propostas pela equipe chegavam a um esvaziamento. A passagem do plano micro ao plano macropolítico apresentava-se enrijecida. Os processos decisórios ficavam estagnados e a governabilidade dos serviços de saúde mental do município era precária, à medida que os atores envolvidos nesse processo de produção de saúde encontravam-se paralisados ante a postura distante e pouco flexível do gestor municipal de saúde.

Nos escritos que seguem, trataremos do relato de nosso percurso pela intervenção proposta no curso de especialização. No desenrolar do processo colocaremos em análise nossa implicação com a PNH, inserida no movimento da Reforma Psiquiátrica Brasileira; a função apoio institucional na construção de nosso Plano de Intervenção; o processo de avaliação e monitoramento da intervenção a partir da $\mathrm{PNH}$; a reconfiguração de nossa proposta; o trabalho em redes e a organização de um Seminário de Humanização, pela Unidade de Produção do curso. São alguns pontos que consideramos fundamentais dentro dessa experiência de apoio institucional à PNH.

\section{0 desenrolar do processo}

Nesse percurso formativo trabalhamos o conceito de intervenção desde uma perspectiva processual, em que a mudança almejada não é uma mudança antecipável e por esse motivo as metas não estão dadas de antemão - elas se constroem ao longo do processo, são inerentes a ele. Paulon (2005, p.22) refere que "ao operar no plano dos acontecimentos, a intervenção deve guardar sempre a possibilidade do ineditismo da experiência humana, e o pesquisador a disposição para acompanhála e surpreender-se com ela".

Dessa forma, essa experiência de inserção como apoiadora institucional da PNH consistiu na experiência de interporse em um processo que já estava em andamento e de atravessar os processos de trabalho da equipe, dando passagem ao movimento coletivo. Tratou-se da tessitura de uma intervenção no interior do coletivo em que também nos inserimos como mais uma trabalhadora da saúde - em posição de paridade com os colegas apoiados - ao cartografar os movimentos do coletivo e nosso próprio movimento de apoiadora institucional. Encontramos a possibilidade de avanços, retrocessos, paralisações, construção de projetos, mudança de rumos 
e avaliação - todos eles movimentos entendidos dentro de um mesmo processo.

Nosso campo de análise e de intervenção teve como espaço privilegiado as reuniões da equipe multiprofissional que compunha o trabalho em saúde mental no CAPS II do município em que atuávamos. A seguir, serão analisados alguns elementos de nossa trajetória no apoio institucional, a começar pela análise de nossa implicação com a Política Nacional de Humanização.

\subsection{Por que a PNH?}

O SUS é uma política pública em construção. Ancorada na legislação federal (Constituição Federal/1988; Lei 8080/1990; Lei 8142/1990), tem propiciado grandes avanços lado a lado com o surgimento de novas questões a serem pensadas a partir de sua implantação. Está em constante movimento, encontrando novos desafios a cada dia. Desafios que dizem respeito ao acesso com qualidade aos serviços e aos bens de saúde, à ampliação do processo de co-responsabilização entre trabalhadores, gestores e usuários nos processos de gerir e de cuidar; à valorização dos trabalhadores de saúde; à vinculação destes com os usuários (Brasil, 2008a). Enfim, desafios que se referem aos modos de cuidar e aos modos de gerir os processos de produção de saúde em nosso país. Desafios que indicam a necessidade de mudanças.

E para que ocorram mudanças no modelo de atenção, é preciso que também se façam mudanças no modelo de gestão, conforme estabelece o Documento Base da Política Nacional de Humanização (Brasil, 2008a, p.8). Nesse contexto de produção da PNH, Barros e Passos (2005a, p.391) apontam que a humanização se trata de uma "estratégia de interferência nas práticas de saúde levando em conta que sujeitos sociais, atores concretos e engajados em práticas locais, quando mobilizados, são capazes de, coletivamente, transformar realidades transformando-se a si próprios neste mesmo processo". Os autores apostam no exercício de um modo coletivo e cogestivo de produção de saúde e de sujeitos implicados nesta produção.

É importante ressaltar que a concepção de coletivo que engendra esse conceito de humanização não é uma concepção trivial do que seja um coletivo. Barros e Passos (2005b) remetem a reflexão sobre essa concepção ao funcionamento da máquina do Estado, com seu intrincado poder ali expresso em programas, projetos, burocracias, instâncias e esferas de governo político. 
Referem que a complexidade dessa máquina faz de seu interior um mundo que tende a nos atrair e capturar. Todavia, os autores ponderam que, apesar dessa tendência à interiorização, há na máquina do Estado um fora que insiste e que é nomeado por eles como plano do coletivo. Trata-se do espaço em que a política se consolida como experiência pública ou respública.

É nesse fora do Estado, nesse plano do coletivo - no qual a saúde se apresenta como uma questão pública - que a aposta na humanização das práticas de saúde impõe, para os autores supracitados, que a relação entre Estado e política pública seja repensada. Referem que, no momento em que esses dois termos não são mais tomados como coincidentes, quando o domínio do Estado e o do público não mais se justapõem, não se pode aceitar como dada a relação entre eles. Se o público diz respeito à experiência concreta dos coletivos, ele está em um plano diferente daquele do Estado como figura da transcendência moderna. O plano do público é aquele construído a partir das experiências de cada homem. Assim, humanizar as práticas de atenção e gestão em saúde é levar em conta a humanidade como força coletiva que impulsiona e direciona o movimento das políticas públicas (Barros e Passos, 2005b).
É por esse motivo que Barros e Passos lembram que "da política de governo à política pública não há uma passagem fácil e garantida" - vide o contexto sempre atual de disputa entre saberes-poderes no plano da saúde mental, lugar de onde falamos. Apontam que “construir políticas públicas na máquina do Estado exige todo um trabalho de conexão com as forças do coletivo, com os movimentos sociais, com as práticas concretas no cotidiano dos serviços de saúde" (Barros e Passos, 2005a, p.391). Este trabalho de conexão se faz imprescindível quando nos deparamos com o fato de que não basta que haja uma gestão municipal engajada aos princípios do SUS, é preciso que o trabalho concreto no território seja sustentado ao longo do tempo pelos coletivos para que a política de governo se transmute em política pública, política de todos. As alterações da experiência coletiva é que garantem o sentido público das políticas que também atravessam o Estado. A PNH se propôs a operar neste limite entre a máquina do Estado e o plano coletivo, apostando que as políticas públicas devem prevalecer na orientação das ações governamentais.

No cenário local de nossa intervenção, imbricavam-se os desafios da implantação do SUS com os de outra luta que também apresenta fundamentos 
ambiciosos, que é a luta pela consolidação da Reforma Psiquiátrica (Lei 10216/2001), no campo das práticas em Saúde Mental Coletiva onde o CAPS se insere. É possível pensar na articulação desses dois movimentos sociais como solo fértil para o advento da Política de Humanização, que vem na esteira da luta pela integralidade do cuidado ao portador de sofrimento psíquico. SUS, Reforma Psiquiátrica e PNH - temos aí a confluência de três conjuntos teórico-práticos bastante complexos sustentados por um posicionamento ético comum: a defesa da vida.

Reis e colegas (2004) apontam que o campo da Saúde Mental antecipou o movimento mais geral de humanização na Saúde, tendo abrigado uma das primeiras e mais radicais manifestações em prol da humanização no setor dentro do Sistema de Saúde - através da luta antimanicomial pelo fato de "ali vicejarem as condições mais deletérias, mais desumanas no campo da Saúde, afetando e brutalizando a todos, clientes internos e externos" (Reis; Marazina e Gallo, 2004, p.39).

$$
\text { Esses movimentos vêm }
$$

proporcionando o estabelecimento de relações mais solidárias entre trabalhadores, usuários e gestores; de respeito e inclusão das diferenças entre esses sujeitos e de acolhimento à dimensão do sofrimento nas práticas de cuidado. Aqui se pode considerar que uma política de humanização consistente seja uma rede de amparo e continência para usuários e profissionais que nela estão implicados, como "uma instância de libertação real de seus sujeitos" (Reis, Marazina e Gallo, 2004, p.43).

Assim como o SUS, o movimento da Reforma Psiquiátrica, no campo da Saúde Mental, também precisa ser tomado do ponto de vista processual e nessa medida, ser analisado a partir da consideração de seus avanços e desafios. Nas linhas que seguem, trataremos de nossa inserção como apoiadora institucional nesse intrincado campo de intervenção.

\subsection{Do encontro com a Política}

\section{Nacional de Humanização: asas à esperança equilibrista}

Nossa inserção no curso de especialização em Humanização da Atenção e Gestão do SUS e nosso encontro com a PNH ocorreram de forma intensa e carregada de otimismo. Concomitante ao início daquele percurso formativointerventivo alavancava-se no Departamento de Saúde Mental do município um processo de supervisão clínico- institucional, financiado pelo 
Ministério da Saúde dentro do programa de qualificação dos CAPS.

Esse fato acelerou inicialmente o movimento institucional e logo de saída tivemos a articulação para a implantação de um Colegiado Gestor do Departamento. Foi composto por dois integrantes de cada serviço da rede - CAPSII, Ambulatório de Álcool e Drogas e Núcleo Infanto-Juvenil de Atendimento em Saúde Mental - os quais foram denominados Apoiadores Institucionais. Foi num duplo movimento que a nossa inserção teve lugar: enquanto apoiadora institucional do CAPS II no Colegiado Gestor e como apoiadora institucional da PNH no Departamento.

De partida, avaliamos a necessidade de legitimar esse colegiado, que teve a aprovação do Diretor de Saúde Mental, mas que certamente encontraria entraves junto à Secretaria Municipal da Saúde, não afeita às práticas de gestão participativa. Naquele momento, avaliamos que nosso Plano de Intervenção pudesse ser baseado na implantação do dispositivo Colegiado Gestor.

\subsection{O apoio institucional e o desenrolar} do fio da esperança equilibrista: o plano de intervenção

\author{
A função apoio institucional \\ constitui-se como ferramenta para a
}

atualização das diretrizes da PNH em agenciamentos coletivos concretos. Conforme Campos (2007), a função apoio é resultante da ação de sujeitos que "atravessam" o processo de trabalho de coletivos, ajudando-os nas tarefas de qualificar suas ofertas clínicas e de saúde pública, de um lado, e ampliar o grau de grupalidade, de outro lado. Além disso, pode ser entendido como uma tarefa com o propósito de ajudar as equipes a se constituírem em novas relações de poder, mais democráticas, conformadoras de novos modos de subjetivação, o que permitiria a ampliação de sua capacidade operativa, ela mesma afirmativa de uma nova grupalidade (Pasche, 2007). Assim entendemos a função apoio como ferramenta privilegiada para a sustentação de práticas co-geridas.

No arcabouço teórico-prático da PNH, “a co-gestão é um modo de administrar que inclui o pensar e o fazer coletivo, para que não haja excessos por parte dos diferentes corporativismos e também como uma forma de controlar o estado e o governo. É, portanto, uma diretriz ética e política que visa motivar e educar os trabalhadores" (Brasil, 2007, p.8). O exercício da co-gestão se dá nos espaços coletivos, que segundo Campos são "arranjos concretos de tempo e lugar, em que o poder esteja em jogo; e onde, de 
fato, se analisem problemas e se tomem deliberações" (Campos, 2007, p.42). Aí os modos de se construir democracia engendrariam a constituição de sujeitos potentes para sustentá-la.

$\mathrm{O}$ autor alerta que a co-gestão de coletivos organizados para a produção depende de vontade política e de condições objetivas. Acrescenta que o Método da Roda $^{2}$, que fundamenta a PNH, se propõe a construí-las com a máxima racionalidade possível (Campos, 2007).

Diante das características do cenário exposto, nossa intervenção como apoiadora institucional da $\mathrm{PNH}$ passou pela sustentação do espaço coletivo de trocas, as rodas de conversa, bem como pelo agenciamento de forças para que as decisões do coletivo fossem encaminhadas aos setores competentes pelo gestor do Departamento. Os objetivos consistiriam em agenciar o incremento da grupalidade e do protagonismo para realizar pactuações, no sentido da democratização das relações de trabalho.

No princípio havia a intenção de que a implantação do Colegiado Gestor pudesse ser dispositivo para o alcance desses objetivos. Pensávamos que o avanço desse movimento inicial é que propiciaria o surgimento de condições de possibilidade para a inserção de outros dispositivos da PNH no serviço e no município. Isso implicaria na infiltração de novos modos de gerir e de cuidar, com a oferta de alternativas e a aproximação com a Secretaria de Saúde, o que requereria contágio e articulação com novos parceiros.

\subsection{Avaliação e monitoramento: pensar e andar no justo tempo, à moda do equilibrista}

O monitoramento do processo de intervenção apontou para a precariedade e fragilidade da vontade política e das condições objetivas para a co-gestão dos coletivos através do Colegiado Gestor no cenário da Saúde Mental no município. Essa constatação propiciou uma torção na direção de nosso trabalho. Foi como se confrontássemos o modelo por nós idealizado do dispositivo do Colegiado Gestor com a realidade que se apresentava aos nossos olhos. Naquelas condições, passamos a entender a necessidade de haver um fortalecimento da noção de grupalidade e de coletividade na equipe, através do apoio institucional, para então caminharmos numa direção sustentada pelo desejo coletivo.

Santos-Filho (2008) destaca que a avaliação deve ser realizada de modo a refletir a complexidade e a especificidade dos processos de intervenção. Para ele, a avaliação deve ser investida como 
dispositivo da PNH, "valorizando não somente os resultados dos processos, mas o próprio processo/movimento [em sua potência participativa e ampliada]" (Santos-Filho, 2008, p.2). Assim, o autor alerta que "é preciso escapar do risco de apreendê-los [os dispositivos] em uma perspectiva burocrática de implantação/estruturação e de sua aferição".

O autor refere que não há sentido em se recortar como indicador apenas a existência, a implementação ou não do dispositivo. O que interessa é averiguar, no contexto da intervenção, o sentido que lhe é atribuído pelos sujeitos, se ele traz em si um novo modo de existir e de fazer, se ele transforma o cotidiano do serviço de saúde (Santos-Filho, 2008, p.5). A seguir, descreveremos alguns elementos que compuseram nossa análise e contribuíram para um desvio estratégico na intervenção proposta.

\subsubsection{Parada avaliativa: o coletivo na corda bamba}

O estabelecimento do Colegiado Gestor do Departamento de Saúde Mental consistiu em uma tentativa de articulação para obter avanços no trabalho realizado, principalmente em termos gerenciais. Tentativa esta que partiu do interior das três equipes de saúde mental do município, sem as devidas pactuações com a Secretaria de Saúde. A busca de sua legitimação perante esta instância de gestão estagnou em função da paralisação em que nos encontrávamos diante da indisponibilidade do gestor municipal para o diálogo e para a construção coletiva. Assim, o Colegiado foi se deparando com uma carência de poder deliberativo e de governabilidade, tendo um papel estritamente consultivo. Sua função consistia em instrumentalizar tecnicamente o Diretor do Departamento para a tomada de decisões, à medida que a Secretaria não demonstrava abertura para a realização de fóruns participativos.

As falas dos profissionais da equipe também apontaram para a necessidade de construção coletiva do papel do Colegiado Gestor, pois foi ficando claro que sua constituição ocorreu de forma apressada, sem a necessária discussão para o estabelecimento de consensos e para a apropriação desse processo pelas equipes. Santos-Filho (2009), ao discorrer sobre o perigo da implementação do dispositivo do Colegiado Gestor de forma burocrática acrescenta que

$\begin{aligned} & \text { uma prática discursiva em toda a sua } \\ & \text { potencialidade } \\ & \text { produzir/fomentar autonomia) ainda é } \\ & \text { incipiente no cotidiano dos serviços, e } \\ & \text { tanto as ações (focos, prioridades, }\end{aligned}$


escolhas) quanto os conflitos institucionais, são pouco problematizados e direcionados no espaço do coletivo (Santos-Filho, 2009, p.2-3).

Além disso, vínhamos questionando ao longo do processo do curso a viabilidade de nos colocarmos enquanto apoiadores institucionais em nosso local de trabalho, na própria equipe a qual integrávamos. Moura e colegas (2003, p.175) referem que o importante nas práticas de intervenção institucional é “a constatação de que a presença de um terceiro é indispensável”. Em nosso caso, avaliamos que a Unidade de Produção (UP) do curso de especialização ocupou esse lugar. Costumávamos colocar em análise nesse coletivo nossas práticas enquanto apoiadores nos locais de trabalho.

E foi a partir dos encontros da UP que pudemos formular o entendimento de que ainda não era possível que o Colegiado Gestor da Saúde Mental tivesse legitimidade, pois sequer os serviços possuíam coordenadores autorizados e legitimados. Existiam alguns passos anteriores ao Colegiado Gestor, no que dizia respeito à visibilidade do Departamento de Saúde Mental dentro da Secretaria de Saúde e à conformação de uma política de saúde mental.
Os movimentos institucionais foram desacelerando gradativamente no decorrer do percurso, principalmente com a chegada do período das férias de verão. A supervisora clínico-institucional afastouse do contexto da intervenção, o momento de transição política na administração municipal - entre o final de um mandato e o início do mandato seguinte - durou cerca de três meses e nesse ínterim o Colegiado Gestor esmoreceu.

Nesse cenário, a questão fundamental com que nos deparávamos é expressa com propriedade por Campos (1998, p.864): “Como combinar democratização institucional com capacidade operacional e, portanto, com algum grau de centralização vertical, sem o qual os estabelecimentos se perderiam em discussões intermináveis ou em particularismos?".

E justamente, a diretriz da cogestão apresenta o desafio de manter um certo grau de centralidade lado a lado com a democratização das relações. $O$ que ocorria em nosso campo de intervenção era que a auto-análise da equipe não a levava a uma auto-organização (Baremblitt, 1992/2002). Ela vinha se perdendo sim em discussões intermináveis e em particularismos, conforme aponta Campos (1998). Observávamos que nesses momentos instalava-se o silêncio, o 
sentimento de solidão e a procura de saídas individuais pelos trabalhadores.

Entendemos que o movimento da roda tenha estagnado, de certa forma, pela ausência da necessária institucionalidade da gestão da Saúde Mental, conseqüência do excesso de controle na autoritária gestão da Secretaria de Saúde. O monitoramento e a avaliação dos processos de produção de saúde eram práticas inexistentes no município. O campo da Saúde Mental sequer tinha visibilidade dentro da Secretaria, à medida que os dados referentes à atenção prestada não eram transformados em informações, o que emperrava inclusive o faturamento dos serviços.

Essa realidade apontava para o predomínio de uma lógica manicomial na gestão da Saúde e, por conseqüência, da Saúde Mental do município. Sabemos que a reprodução de modos altamente verticalizados de gerir o trabalho expropria os sujeitos envolvidos, sejam trabalhadores ou usuários, de seus saberes e de seu poder contratual (Kinoshita, 1996).

Aprendemos que o apoiador institucional da PNH na saúde mental tem o papel de tensionar a reflexão sobre as práticas da equipe, ao colocar a questão sobre "o quanto manicomial ainda vamos ser?". Sempre que trabalharmos em uma lógica de fragmentação e alienação dos processos de trabalho, de predomínio de interesses individuais, de desresponsabilização pela assistência oferecida, de isolamento do serviço, de centralização das decisões, de hierarquização corporativista e de disciplinamento e controle sobre os usuários estaremos no ápice da lógica manicomial (e do SUS que dá errado ${ }^{3}$ ).

\subsection{Reconfiguração da intervenção: o apoio institucional e o trabalho de}

\section{formiguinha}

Apostamos, desde o início do curso, na sutileza como requisito para a construção de uma proposta de intervenção, com o cuidado de não impor a entrada da PNH no serviço, de forma a não reproduzir a forma de operar da gestão municipal da saúde - principalmente pelo fato de que o apoio institucional não estava sustentado pelo desejo da equipe, tampouco do gestor.

Todavia essa aposta - como a própria palavra denota - não se deu sem investimento ou sem expectativas. Então a experiência do esmorecimento do movimento da roda trouxe certa frustração. Frustração que também deu lugar à compreensão de que o esmorecimento se deu porque o movimento não tinha a necessária sustentação em termos de 
condições objetivas para a gestão participativa. Tratava-se de mais um analisador do cenário, em relação ao processo de trabalho da equipe e do contexto em que ele estava inserido.

Assim o trabalho passou por uma reconfiguração, tendo como foco o plano micropolítico. Aí foi possível o entendimento de que era preciso aguardar o tempo da equipe, fazendo o exercício de sustentar o trabalho sem tantas expectativas, acompanhando seu movimento, traduzindo e fazendo devoluções sobre seu processo oportunamente até o surgimento das demandas do grupo, considerando a dimensão dos limites da função apoio, ainda que exercida por um par e sem quaisquer contratualizações. Passamos a levantar questionamentos sobre como produzir uma zona comum, como contagiar para o trabalho em rede, como produzir saúde onde estava instaurada a doença.

Entendemos o trabalho com a diretriz da Co-gestão como forma de produzir espaço potencial para a constituição de coletivos co-geridos. Apostar na co-gestão é dar passagem ao potencial criativo e gestionário dos coletivos de trabalho, aliados aos interesses e contribuições da comunidade, com a necessária centralidade operacional do gestor. E essa aposta da PNH, na potencialidade da co-gestão, pode ser entendida como aposta na produção de saúde para todos os sujeitos envolvidos nas práticas de cuidado. Aí também é possível articular a diretriz da Valorização do Trabalho e do Trabalhador em Saúde (Brasil, 2008b), pois é a partir do fortalecimento da capacidade individual e coletiva para transformar as situações que agridem e fazem sofrer (Barros, Mori e Bastos, 2006), da constituição de grupos capazes de impor resistências às determinações adversas do meio (Campos, 1998), que se estará promovendo saúde nos locais de trabalho.

Nesse sentido que foram sendo ampliados os espaços de construção coletiva entre os profissionais. Além de buscarmos a co-responsabilização pelos atendimentos por parte da equipe do CAPS, iniciamos um processo de abertura para o diálogo com outros serviços que em algum momento atendiam os mesmos usuários. Tornou-se possível agendarmos atendimentos conjuntos nas comunidades, acompanharmos o paciente quando hospitalizado, trabalharmos na lógica da co-responsabilização pelo cuidado. Ocorreram movimentos importantes no cenário, que foram movimentos parciais. Nem toda equipe tinha o mesmo entendimento sobre os modos de fazer 
clínica naquele contexto e nem toda a equipe trabalhava de forma homogênea. Naquele coletivo de trabalho, cada profissional sentia-se convocado de maneira diferente do outro. Cada vez mais os pacientes também foram chamados a participar das decisões e dos debates sobre a organização do serviço. Com isso, os gestores passaram a ser demandados, de alguma forma, a estarem mais atentos para as questões da saúde mental do município (Eidelwein, 2010).

Em outras palavras, nos deparamos com a necessidade de respeito às relações e de estabelecimento de relações de composição. Adentramos o campo da ética, que segundo Sant'Anna (2001, p.95) é entendida como "o estabelecimento de relações nas quais, no lugar da dominação, se exercem composições entre os seres". Relações provisórias e essenciais, "que tornem supérfluo não mais os homens, nem mais a vida, mas sim as relações de dominação com o mundo em favor de encontros que potencializem, num mesmo gesto, a composição individual e a composição coletiva" (Sant'anna, 2001, p.97).

Com o reposicionamento de nosso olhar para o cenário, a partir do dispositivo da Avaliação e Monitoramento da PNH, pudemos vislumbrar outro movimento, mais sutil, que se instalava na equipe. Um movimento relativo à clínica.

Foram disparados processos de tomada de decisões no coletivo no que dizia respeito à clínica que queríamos produzir - o que dava lugar à discussão e opção da equipe pelo modelo psicossocial. A partir das discussões de casos em reuniões, tornou-se possível identificar alguns momentos paradigmáticos na construção coletiva de um modo de cuidar. Passamos a perceber aí a existência de uma potente linha de fuga.

Houve um momento paradigmático no serviço, de atendimento a uma situação de crise, em que se operou uma diferença nos modos de acolher, avaliar e intervir em uma situação de crise. $\mathrm{O}$ atendimento estava sendo realizado por três profissionais, sendo uma enfermeira, uma psicóloga e uma médica psiquiatra, a qual tomou a decisão de encaminhar o usuário em crise para a internação psiquiátrica compulsoriamente - à medida que ele não concordava em utilizar esse recurso da rede - e sem consultar às suas colegas. Estas decidiram sustentar um posicionamento contrário àquela conduta da médica, apostando na possibilidade de oferecer um cuidado intensivo ao usuário no próprio CAPS. Essa diferença consistiu, fundamentalmente, na escuta do usuário, com a decorrente inclusão do sujeito na 
construção de seu projeto terapêutico singular.

Tratar cada caso em sua singularidade exige esforços teóricos e práticos importantes, à medida que os procedimentos não mais estão dados de antemão. Apesar dessa exigência, foi possível que houvesse no serviço uma torção nesse sentido. Pouco a pouco as indicações clínicas foram deixando de ser genéricas e passaram a ter fundamentação em uma história de vida, em recursos sociais, familiares, da rede de serviços e na vinculação com o CAPS. E com isso, a palavra foi conquistando o estatuto de recurso terapêutico, a ser construído na própria experiência (Eidelwein, 2010).

\subsection{O trabalho em redes como}

dispositivo de coletivização das práticas em saúde

Em um dos eixos do curso de especialização trabalhamos com o conceito de redes e tivemos a proposta de realizar uma produção coletiva no espaço da Unidade de Produção. Este momento constituiu-se como um ponto alto de nosso processo como apoiadores institucionais. Deparamo-nos com um espaço coletivo, de certa forma protegido, em que reproduzimos, na execução do trabalho, situações vivenciadas no cotidiano do trabalho em equipe. Espaço protegido porque aberto a análise do processo, numa vivência do coletivo em ato. Nessa análise emergiram os ruídos, a tentativa de construção de saídas individualizantes e as dificuldades com a inclusão da alteridade.

Remetemo-nos ao nosso trabalho na equipe do CAPS e passamos a considerar a necessidade de perceber $o$ trabalho desenvolvido dentro de uma rede ampliada, com vistas à abertura de básculas nas práticas no serviço. Abertura que colocasse em análise o autocentramento em que recaíam nossas práticas, reproduzindo a lógica manicomial, quando acreditávamos que os conflitos vivenciados na saúde mental do município diziam respeito tão-somente aos seus trabalhadores.

Apesar dos movimentos disparados, o CAPS II apresentava certos problemas relativos à concepção do serviço. Ali conviviam iniciativas de conformação de um sistema intensivo de cuidados em saúde mental, um ambulatório de psiquiatria, um centro de convivência diferentes dispositivos de cuidado de uma rede de saúde mental operando em um só lugar. O serviço era chamado na cidade como "A Saúde Mental", talvez porque fosse o único equipamento da rede de saúde do município que de fato se 
propunha ao atendimento nessa área. A partir de nossa incursão pela política de humanização do SUS e da conseqüente reflexão sobre os processos de trabalho no local, identificamos uma necessidade de abertura comunicacional para o trabalho com redes sociais, de forma a transversalizar as práticas de saúde mental e assim trabalhar a partir do modelo de atenção psicossocial.

Nesse percurso, alguns movimentos de abertura puderam ser disparados. A própria inserção no curso pode ser tomada como dispositivo de coletivização e publicização das práticas em saúde mental no município. A conexão na rede HumanizaSUS foi uma forma de estabelecer contato com a produção nacional relativa à $\mathrm{PNH}$. A organização de um Seminário Regional de Humanização em parceria entre duas UP's também veio nesse sentido de ventilar saberes e experiências de trabalhadores do SUS pela cidade.

Esse Seminário ocorreu no município em que realizamos o apoio institucional, o que permitiu que o cenário que vínhamos descrevendo e problematizando ao longo do curso pudesse ser experimentado pelos colegas das UP's na organização do evento, produzindo questionamentos sobre a receptividade da gestão municipal à política de humanização. Mais uma vez o grupo de trabalho de nossa Unidade de Produção pôde funcionar como terceiro, colocando em análise o processo de construção do Seminário, os entraves encontrados e a dinâmica das relações de poder na administração municipal.

Essa experiência veio reforçar nossa opção pelo trabalho micropolítico, à medida que lançou um foco de luz sobre o cenário, explicitando que a construção de uma política pública somente pode ter lugar com efetiva participação dos envolvidos.

\section{Considerações Finais}

Ao longo de nossa trajetória pelo Curso de Especialização em Humanização da Atenção e Gestão do SUS propusemos uma intervenção fundamentada na diretriz da Co-gestão, utilizando como ferramenta o apoio institucional, lançando-nos na busca da criação de condições de possibilidade para a inserção de dispositivos de humanização na Saúde Mental.

No que diz respeito à gestão do trabalho, foi possível problematizar alguns pontos, "a passos de formiguinha". Existiam entraves político-institucionais importantes, relacionados à gestão técnica e administrativa, nos quais esbarravam as decisões da equipe de trabalhadores do 
CAPS II. Aí se manifestava uma lógica totalitária/manicomial, a partir da qual as questões da saúde mental não ultrapassavam as paredes do serviço, que se encontrava isolado do restante da rede de saúde. Nesse ponto, a clínica encontrava obstáculos decisivos diante da precariedade das condições de trabalho.

Explicitou-se nesse percurso a inseparabilidade entre atenção e gestão, entre clínica e política, entre sujeito e coletivo. Essa explicitação também foi um processo sustentado pelo apoio institucional, com o objetivo de incrementar a transversalidade, a grupalidade e a coletivização das práticas na equipe. Somente quando ela pode se reconhecer como sujeito coletivo é que pode lutar pela democratização e pela possibilidade de co-gestão de seus processos, e assim trabalhar com a produção de saúde e de sujeitos. Essa luta precisava começar de dentro, para aí acionar instâncias ampliadas de gestão e de participação social. Tratava-se de um trabalho micropolítico, de formiguinha mesmo - ou será de equilibrista?

\section{Notas}

Trabalho inédito, resultado de ensaio monográfico de conclusão do curso de Especialização em Humanização da Atenção e da
Gestão

do

SUS, MS/UFRGS/ESPRS, edição 2008.

O Método da Roda ou Método Paidéia (Campos, 2007) consiste em um modo de fazer gestão para coletivos considerando a produção de sujeitos mais livres, autônomos e corresponsáveis pala coprodução de saúde.

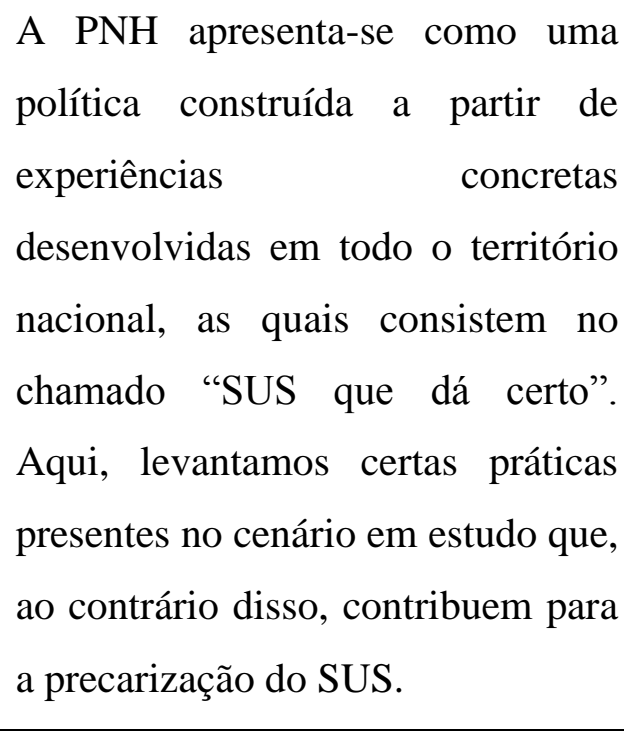

\section{Referências}

Almeida, f. L.; Lopes, f. C.(2004) $O$ equilibrista. 11.ed. São paulo: editora ática.

Baremblitt, G.(2002) Compêndio de análise institucional $e$ outras correntes: teoria e prática. 5.ed. Belo horizonte: instituto felix guattari.

Barros. M. E.b.; mori, m. E.; bastos, s. (2006). O desafio da política nacional de humanização nos processos de trabalho: o instrumento “programa de formação em saúde e 
trabalho". Cadernos saúde coletiva, v. 14, n.1, p.31-48.

Barros, r. D. B.; Passos, e.(2005a) Humanização na saúde: um novo modismo? Interface - comunic., saúde, educ., v.9, n.17, p.389-406.

.(2005b) A humanização como dimensão pública das políticas de saúde. Cadernos saúde coletiva, v. 10, n. 3, p. 561-571.

Brasil.(2003) Conselho nacional de secretários de saúde. Legislação do sus / conselho nacional de secretários de saúde. Brasília: conass.

ministério da saúde.(2007) Secretaria de atenção à saúde. Núcleo técnico da política nacional de humanização. gestão participativa: co-gestão. Brasília: editora do ministério da saúde.

ministério da saúde.(2008a)

Secretaria de atenção à saúde. Núcleo técnico da política nacional de humanização. Humanizasus: documento base para gestores e trabalhadores do sus. Brasília: editora do ministério da saúde. , ministério da saúde.(2008b) Secretaria de atenção à saúde. Núcleo técnico da política nacional de humanização.trabalho e redes de saúde : valorização dos trabalhadores da saúde. Brasília: editora do ministério da saúde.

Campos, g. W. S.(1998) O anti-taylor: sobre a invenção de um método para co-governar instituições de saúde produzindo liberdade e compromisso. Cadernos de saúde pública, v.14, n.4, p. 863-870. (2007) Um método para análise e co-gestão de coletivos: a constituição do sujeito, a produção de valor de uso e a democracia em instituições: o método da roda. 3.ed. São paulo: hucitec.

Eidelwein, C.(2010) A escuta do sujeito e a abertura à outra cena no trabalho em saúde mental. Correio da appoa, v. 193, p. 20-24.

Kinoshita, r. T.(1996) Contratualidade e reabilitação psicossocial. In: pitta, a. (org.). Reabilitação psicossocial no brasil. São paulo: hucitec, p. 1-158.

Moura, a.h.(2003) et al. Análise do trabalho institucional nas equipes dos distritos sanitários e no hospital mário gatti de campinas. In: campos, g.w.s. saúde paidéia. São paulo: hucitec, p.167-185.

Pasche, d. F. (2007) A reforma necessária do sus: inovações para a sustentabilidade da política pública de saúde. Ciênc. Saúde coletiva, v. 12, n. 2, p.307-317. 
Paulon, s.(2005) M. A análise de implicação como ferramenta na pesquisa-intervenção. Psicologia $e$ sociedade. V.17, n.3, p. 16-23.

Reis, a.o.a.; marazina, i.v.; gallo, p.r.(2004) a humanização na saúde como instância libertadora. Saúde $e$ sociedade. V.13, n.3, p.36-43.

Sant'anna, d. B.(2001) Corpos de passagem: ensaios sobre a subjetividade contemporânea. São paulo: estação liberdade.

Santos-filho, s. B.t. um olhar sobre o trabalho em saúde nos marcos teórico-políticos da saúde do trabalhador e do humanizasus. Disponível em http://bvsms.saude.gov.br/bvs/public acoes/olhar_sobre_trabalho.pdf Acesso em jan. 2009. .(2008) Construindo um método de acompanhamento avaliativo e avaliando processos de formação: em foco o curso de humanização da atenção e gestão em saúde do mato grosso. Relatório de consultoria apresentado para o ministério da saúde. Brasília.

Carolina Eidelwein: É psicóloga na SESRS, Especialista em Humanização da Gestão e Atenção do SUS (UFRGS), mestranda em Psicologia Social e Institucional (UFRGS).

E-mail: caroleindelwein@yahoo.com.br 